\title{
Assessing the Uncertainty Associated with Flood Features due to Variability of Rainfall and Hydrological Parameters
}

\author{
Ahmad Sharafati $\left(\mathbb{D},{ }^{1,2,3}\right.$ Mohammad Reza Khazaei $\left(\mathbb{D},{ }^{4}\right.$ Mohamed Salem Nashwan (D), ${ }^{5,6}$ \\ Nadhir Al-Ansari $\left(10,7\right.$ Zaher Mundher Yaseen $\left(10,{ }^{8}\right.$ and Shamsuddin Shahid $\oplus^{5}$ \\ ${ }^{1}$ Institute of Research and Development, Duy Tan University, Da Nang 550000, Vietnam \\ ${ }^{2}$ Faculty of Civil Engineering, Duy Tan University, Da Nang 550000, Vietnam \\ ${ }^{3}$ Department of Civil Engineering, Science and Research Branch, Islamic Azad University, Tehran, Iran \\ ${ }^{4}$ Department of Civil Engineering, Payame Noor University, Tehran, Iran \\ ${ }^{5}$ Faculty of Engineering, Universiti Teknologi Malaysia (UTM), Skudai, Johor 81310, Malaysia \\ ${ }^{6}$ Faculty of Engineering and Technology, Arab Academy for Science, Technology and Maritime Transport (AASTMT), \\ Cairo, Egypt \\ ${ }^{7}$ Civil, Environmental and Natural Resources Engineering, Lulea University of Technology, Lulea 97187, Sweden \\ ${ }^{8}$ Sustainable Developments in Civil Engineering Research Group, Faculty of Civil Engineering, Ton Duc Thang University, \\ Ho Chi Minh City, Vietnam
}

Correspondence should be addressed to Zaher Mundher Yaseen; yaseen@tdtu.edu.vn

Received 25 September 2019; Revised 16 July 2020; Accepted 10 August 2020; Published 25 August 2020

Academic Editor: Emilio Bastidas-Arteaga

Copyright (C) 2020 Ahmad Sharafati et al. This is an open access article distributed under the Creative Commons Attribution License, which permits unrestricted use, distribution, and reproduction in any medium, provided the original work is properly cited.

\begin{abstract}
An assessment of uncertainty in flood hydrograph features, e.g., peak discharge and flood volume due to variability in the rainfallrunoff model (HEC-HMS) parameters and rainfall characteristics, e.g., depth and duration, is conducted. Flood hydrographs are generated using a rain pattern generator (RPG) and HEC-HMS models through Monte Carlo simulation considering uncertainty in stochastic variables. The uncertainties in HEC-HMS parameters (e.g., loss, base flow, and unit hydrograph) are estimated using their probability distribution functions. The flood events are obtained by simulating runoff for rainfall events using the generated model parameters. The uncertainties due to rainfall and model parameters on generated flood hydrographs are evaluated using the relative coefficient of variation $(\mathrm{RCV})$. The results reveal a higher RCV index for flood volume $(\mathrm{RCV}=153)$ than peak discharge $(\mathrm{RCV}=116)$ for a $12 \mathrm{hr}$ rainfall duration. The average relative RCV (ARRCV) index computed for hydrological component (e.g., base flow, loss, or unit hydrograph) indicates the highest impact of rainfall depth on flood volume and peak. The results indicate that rainfall depth is the main source of uncertainty of flood peak and volume.
\end{abstract}

\section{Introduction}

Reliable estimation of flood characteristics is essential for flood mitigation planning and designing of urban hydraulic structures [1-5]. Numerous models have been developed to relate the rainfall event over a catchment to emanated runoff at catchment outlet $[6,7]$. These rainfall-runoff models are mainly used to predict streamflow and forecasting floods [8].

The prediction of floods using rainfall-runoff models are associated with uncertainty due to the uncertainty in input variables (i.e., rainfall), model parameters (i.e., loss), and model structure [3, 9-14]. The frequency analysis approach is generally used for the estimation of the probable maximum flood (PMF) from the time series of observed peak discharge [15]. The inherent uncertainty of floods is considered as the primary source of uncertainty in such procedure [16-18]. However, a flood occurs for a probable maximum precipitation (PMP) event in a catchment having a favourable hydraulic condition such as saturated soil moisture condition [19]. The PMP is estimated by fitting probability distribution function (PDF) to annual maximum precipitation (AMP) series. The PMP values for different 
return periods are used in a rainfall-runoff simulation model to generate flood hydrographs [20]. The extreme value distributions such as log Pearson, log normal, GEV, and Gumbel are commonly used for fitting AMP time series [21]. Several goodness of fit (GOF) tests are used to find the best fit distribution, which includes the Kolmogorov-Smirnov test, Anderson-Darling test, Akaike information criterion, and Bayesian information criterion [22]. Different GOF tests often provide contradictory results in ranking best fit distribution. Besides, various methods are used for the estimation of fitted PDF parameters such as L-moments, maximum likelihood estimator, generalized maximum likelihood, Bayesian methods, probability weighted moments, least square, and many others [23-25]. Estimated PDF parameter values vary significantly when different methods are used for the estimation of PDF parameters [26].

Besides, inaccuracy in rainfall-runoff model parameters, their scale, and other associated errors impart uncertainty in flood hydrographs [27]. The hydrological model uses various functions to estimate the water flow direction and infiltration loss. Not only the different function provides different flood features but also a slight variation in parameters of the selected functions significantly affects model runoff volume, peak, and other features [28-30]. Therefore, the simulation of floods from rainfall using rainfall-runoff models is always associated with uncertainty. However, uncertainty in the estimation of PMF from maximum annual runoff is only usually evaluated to estimate uncertainty in flood features. The uncertainties associated with stochastic variables such as rainfall, loss, and base flow are often ignored. Recently, a number of studies have been conducted to estimate floods using the rainfall-runoff model considering the uncertainty of effective variables and parameters [31,32]. The uncertainty of the rainfall-runoff model can be generally quantified using four approaches [8]: (i) analytical method where the probability distribution of flood is obtained according to the variables affecting the flood characteristics [33]. Shrestha [8] pointed out that this method is rarely used due to its dependence on the form of the probability distribution functions (PDFs) used and the nonlinearity in model behavior. (ii) Approximation methods such as first-order second-moment (FOSM) and advanced first-order secondmoment (AFOSM) [33-36]. One of the main advantages of these methods is their simplicity as they only require the mean and variance of the input variables. (iii) Sampling methods such as the Monte Carlo simulation (MCS) approach [37-45], which provides the probability distribution of highly nonlinear model output $[35,46]$ and considers the most elegant method among the existing techniques used for uncertainty analysis. (iv) Generalized likelihood uncertainty estimation (GLUE) method [7, 47-53], which is based on the philosophy of avoiding the full probabilistic model specification and search for regional parameters among the prediction and actual observations [54].

To the best knowledge of the current study, the uncertainty analysis of flood hydrograph is conducted using various considerations. The flood hydrographs of Jamishan dam catchment located in Iran are generated using the rain pattern generator (RPG), which is a stochastic rainfall model and a physically based lumped hydrological model known as HEC-HMS. The uncertainties in rainfall duration and depth, as well as HEC-HMS parameters, are considered for the estimation of flood hydrographs. The Monte Carlo simulation is used for the evaluation of uncertainties of input variables and model parameters. The selection of this method is due to its remarkable advantages such as flexible constrained simulation and the potential to account the dependence between input variables. Finally, propagation of uncertainty of input variables/model parameters to the flood hydrographs is studied.

\section{Study Area and Data Description}

The Jamishan basin, located in Kermanshah province, Iran, with an area of $524.07 \mathrm{~km}^{2}$, is used as the case study area in the present study (Figure 1). It is a subbasin of the Seymareh River, which has a $53 \mathrm{~m}$ long and $268 \mathrm{~m}$ wide earth-filled dam (Jamishan dam). Jamishan basin has one rainfall gauge station (the Songhor station) and one hygrometry station (Jamishan station) (Figure 1). Data recorded at these stations are employed to calibrate the HEC-HMS model using eight rainfall events and validate the flood hydrographs for four events.

\section{Methodology}

3.1. Flood Hydrograph Generation. This study assesses the uncertainty associated with flood hydrograph features namely peak discharge and flood volume due to variability of the rainfall-runoff model (HEC-HMS) parameters and rainfall characteristics namely rainfall depth, duration, and pattern. The rainfall events are generated using a stochastic model named rainfall pattern generator (RPG), introduced by Sharafati and Zahabiyoun [13]. The HEC-HMS parameters (e.g., loss, base flow, and unit hydrograph) are achieved using their PDFs. Finally, the flood hydrographs are obtained by simulating runoff from rainfall events using the HEC-HMS model with the generated model parameters. Monte Carlo simulation (MCS) is used to analyse statistical uncertainty based on the probability distribution of variables used for model development. A hydrologist has widely used the MCs as a robust approach for uncertainty analysis [55-57].

3.2. RPG Model. The RPG stochastic rainfall model generates random rainfall events via MCS sampling procedure. The model characterizes a rainfall event in terms of rainfall depth, duration, and rainfall pattern. It assumes that the rainfall pattern is dependent on rainfall depth and duration. To provide the PDFs required for generating the rainfall events, observed data are divided into several depth classes. Subsequently, rainfall events for each depth class are distributed to some duration classes, and the rainfall events in each duration class are categorized into rainfall pattern classes. For each depth class, rainfall duration is extracted using the empirical cumulative probability distribution (CDF) derived from the rainfall events within that class. According to a given rainfall depth and duration, the rainfall pattern is generated based on developed conditional CDF. Therefore, the final output of the 


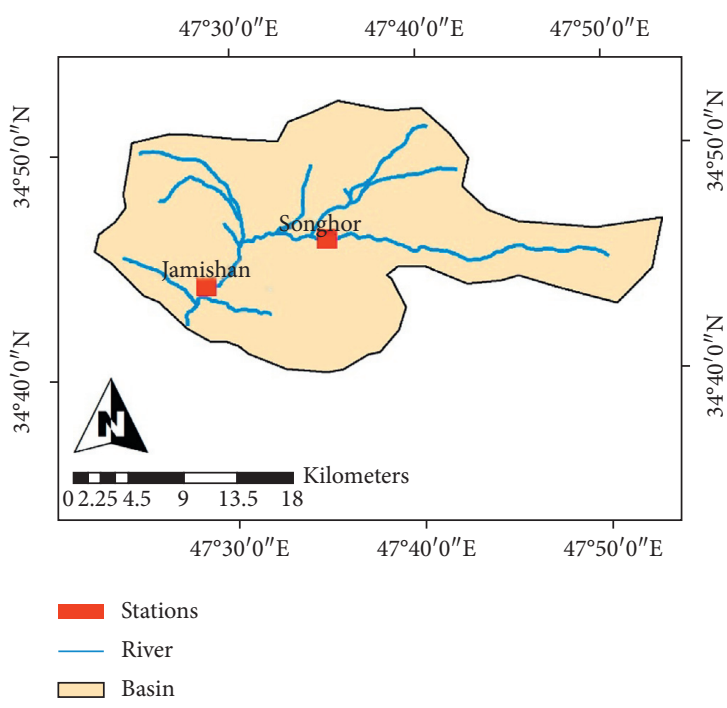

(a)

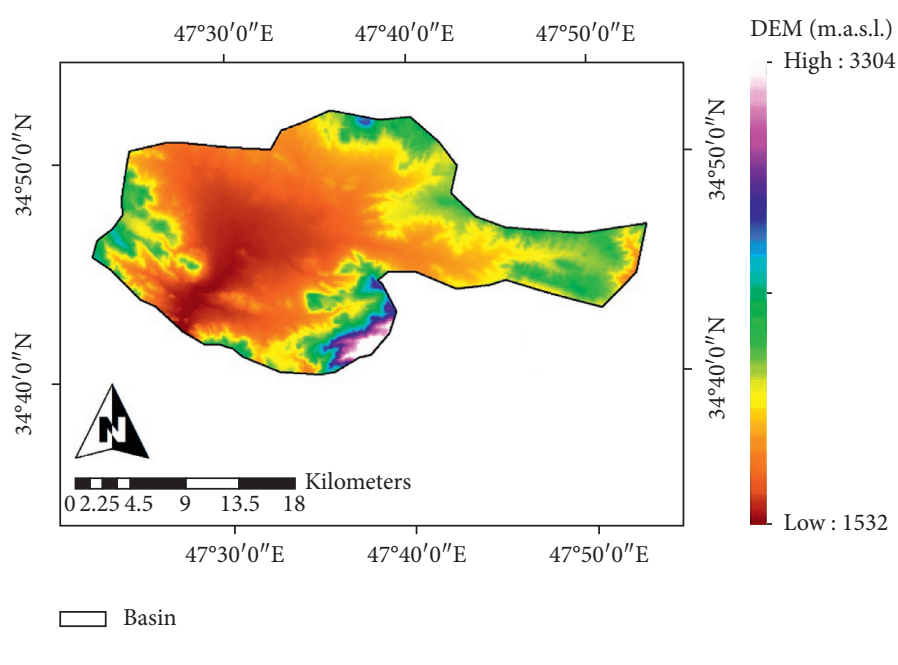

(b)

FIgURE 1: (a) The Jamishan River basin, and (b) the digital elevation model of the basin.

RPG model is a rainfall pattern. In each model run, the normalized rainfall patterns are generated to provide rainfall patterns for the simulated rainfall events. A full description of the model and its operation are available in the study by Sharafati and Zahabiyoun [13].

3.3. HEC-HMS Model. Among various rainfall-runoff simulation models, HEC-HMS has evidenced its capacity to simulate flood patterns effectively [57, 58]. Hence, this model is employed to generate surface runoff based on randomly generated rainfall events. HEC-HMS provides a choice for selection of suitable loss models for estimation of infiltration. In this study, the Green-Ampt method was selected, which includes five parameters, the initial loss (IL), moisture deficit (MD), wet suction (WS), hydraulic conductivity (HC), and impervious area (IA), to estimate the rainfall excess. Subsequently, the SCS unit hydrograph, which utilizes the lag time (LT) parameter, is employed to transfer the rainfall excess to direct runoff. Finally, the base flow is estimated based on exponential formulation, which contains three parameters such as initial flow (IF), recession flow (RF), and recession constant (RC), to combine direct runoff hydrograph to obtain the flood hydrograph at the catchment outlet.

3.4. Assessing Uncertainty Associated with Flood Features. The length of data (number of events) has a direct impact on calibrated values of HEC-HMS parameters. To quantify this source of uncertainty, the HEC-HMS parameters are considered as random variables. The uncertainty related to peak discharge and flood volume due to variability of HEC-HMS parameters and rainfall features are evaluated considering six different cases. A summary of random variables considered in different cases is presented in Table 1.
Case 1 considers only the base flow parameters (e.g., IF, $\mathrm{RF}$, and RC) as random variables. Case 2 and Case 3 consider the loss parameters (e.g., IL, MD, WS, HC, and IA) and unit hydrograph (LT) as the stochastic parameters, respectively. Case 4 is defined to assess the uncertainty associated with rainfall depth. The randomness in characteristics of all the HEC-HMS parameters is considered in Case 5, but the variability of other rainfall features is ignored. Case 6 is used to assess the uncertainty associated with flood features due to the variability of rainfall depth and all the HEC-HMS parameters. The impact of rainfall duration on flood hydrograph is investigated for three different durations $(12 \mathrm{hr}$, $18 \mathrm{hr}$, and $24 \mathrm{hr}$ ) in all the cases.

The PDFs of the HEC-HMS parameters are estimated from eight previously calibrated events $[13,57,58]$. The PDFs (uniform distribution function) of the parameters are obtained based on maximum and minimum values of the parameters calibrated in those studies, which are $\mathrm{IF} \sim \mathrm{U}(0.5,19), \mathrm{RF} \sim \mathrm{U}$ $(2.5,35), \mathrm{RC} \sim \mathrm{U}(0.95,7.57), \mathrm{IL} \sim \mathrm{U}(0.01,1.35), \mathrm{MD} \sim \mathrm{U}(0.06$, $0.55), \mathrm{WS} \sim \mathrm{U}(200,2000), \mathrm{HC} \sim \mathrm{U}(0.07,3.8), \mathrm{IA} \sim \mathrm{U}(1.8,12)$, and $\mathrm{LT} \sim \mathrm{U}(2.51,15.5)$. Besides, the deterministic values of the HEC-HMAS parameters are considered as $I F=10 \mathrm{~m}^{3} \mathrm{~s}^{-1}$, $\mathrm{RF}=35 \mathrm{~m}^{3} \mathrm{~s}^{-1}, \quad \mathrm{RC}=1.42, \quad \mathrm{IL}=0.3 \mathrm{~mm}, \quad \mathrm{MD}=0.45$, $\mathrm{WS}=900 \mathrm{~mm}, \mathrm{HC}=0.22 \mathrm{mhr}^{-1}, \mathrm{IA}=8 \%, \mathrm{LT}=8.34 \mathrm{hr}$, and rainfall depth $=74 \mathrm{~mm}$ [58]. HEC-HMS parameters generated using independent uniform distribution of the parameters and the rainfall events generated using the RPG model are used to estimate flood hydrographs. Ten thousand flood hydrographs are generated using this procedure.

To quantify the impact of uncertainty associated with model parameters and rainfall on flood hydrograph features (peak and volume), a new index named relative coefficient of variation $(R C V)$ is defined as follows:

$$
R C V_{x, y}=\frac{C V_{x}}{C V_{y}}
$$


TABle 1: Description of the cases considered in the present study.

\begin{tabular}{|c|c|c|c|c|c|c|c|c|c|c|}
\hline \multirow{2}{*}{ Case } & \multicolumn{3}{|c|}{$\begin{array}{l}\text { Base flow } \\
\text { parameters }\end{array}$} & \multicolumn{5}{|c|}{ Loss parameters } & \multirow{2}{*}{$\begin{array}{l}\text { Unit hydrograph parameter } \\
\qquad L T\end{array}$} & \multirow{2}{*}{ Rainfall depth } \\
\hline & $I F$ & $R F$ & $R C$ & $I L$ & $M D$ & $W S$ & $H C$ & $I A$ & & \\
\hline Case 1 & $R$ & $R$ & $R$ & $D$ & $D$ & $D$ & $D$ & $D$ & $D$ & $D$ \\
\hline Case 2 & $D$ & $D$ & $D$ & $R$ & $R$ & $R$ & $R$ & $R$ & $D$ & $D$ \\
\hline Case 3 & $D$ & $D$ & $D$ & $D$ & $D$ & $D$ & $D$ & $D$ & $R$ & $D$ \\
\hline Case 4 & $D$ & $D$ & $D$ & $D$ & $D$ & $D$ & $D$ & $D$ & $D$ & $R$ \\
\hline Case 5 & $R$ & $R$ & $R$ & $R$ & $R$ & $R$ & $R$ & $R$ & $R$ & $D$ \\
\hline Case 6 & $R$ & $R$ & $R$ & $R$ & $R$ & $R$ & $R$ & $R$ & $R$ & $R$ \\
\hline
\end{tabular}

$R=$ random and $D=$ deterministic.

where $C V_{x}$ is the coefficient of variation of flood features, e.g., peak discharge $(x=p)$ or flood volume $(x=v)$, and $C V_{y}$ is the coefficient of variation model parameter $(y=$ $I F$ or $R F$ or $R C$ or $I L$ or $M D$ or $W S$ or $H C$ or IA or $L T$ or rainfall depth).

To detect the most influencing hydrological parameters on flood hydrograph features, the average relative RCV (ARRCV) index for the $j^{\text {th }}$ hydrological component (e.g., base flow, loss, or unit hydrograph) is computed as follows:

$$
\begin{aligned}
& A R R C V_{j}=\frac{\sum_{k=1}^{K} R R C V_{k, j}}{K}, \\
& R R C V_{k, j}=\frac{\left(A R C V_{k, j}^{\text {Case } 4}-A R C V_{k, j}^{\text {Case } j}\right)}{A R C V_{k, j}^{\text {Case } j}} \times 100, \\
& A R C V_{i, j}=\frac{\sum_{i=1}^{W} R C V_{i, j}}{W},
\end{aligned}
$$

where $K$ is the number of rainfall durations, which is equal to $3(12 \mathrm{hr}, 18 \mathrm{hr}$, and $24 \mathrm{hr})$ in the present study, and $W$ is the total number of parameters in the $j^{\text {th }}$ hydrological component. For instance, $W$ equals to 5 for loss component. The most effective hydrological component on flood uncertainty has the lowest value of ARRCV index.

\section{Results and Discussion}

4.1. Validation of Flood Hydrograph Generation Methodology. The four observed flood events (Figure 2) are used to validate the model-generated flood hydrographs. Hence, specific number of flood hydrographs is generated using MCs for each observed rainfall event.

The validity of flood hydrograph generation methodology is investigated by comparing observed flood volume and peak discharge within the significant band (90\% confidence interval) of generated hydrographs (Figure 3 ). The results reveal that flood volumes and peak discharges of all observed flood hydrographs are within the significant band of generated flood hydrographs.

4.2. Uncertainty Analysis of Flood Hydrograph. The influence of uncertainty of base flow parameters on simulated flood hydrograph is investigated in case 1 . All the hydrological parameters and rainfall depth are considered deterministic

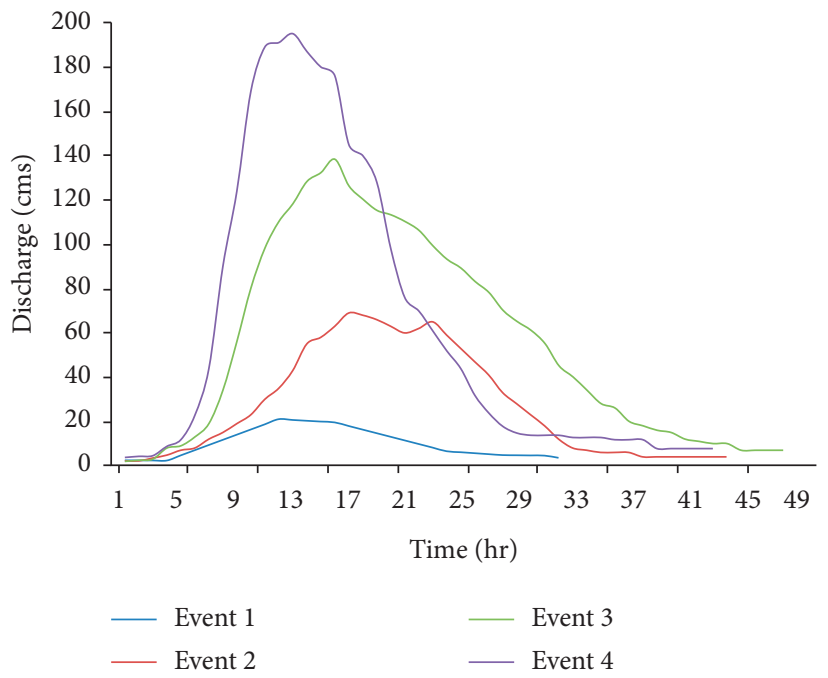

FIgURE 2: Observed hydrographs used to validate the model generated hydrographs.

in this case. The RCV values of the peak discharge and flood volume for stochastic base flow parameters (e.g., IF, RF, and RC) for different rainfall durations (12 hr, $18 \mathrm{hr}$, and $24 \mathrm{hr}$ ) are presented in Figures 4(a)-4(b), respectively. An increasing trend in RCV values of the peak discharge against the rainfall duration is observed, which indicates that uncertainty in peak discharge increases with the increase of rainfall duration. In contrast, no specific pattern in RCV values of the flood volume is observed. The highest RCV value $\left(R C V_{V, R C}=0.17\right)$ is observed for rainfall duration of $12 \mathrm{hr}$. In general, the lowest RCV for both peak discharge and flood volume is obtained for IF parameter, 0.004-0.007 for peak discharge and 0.11-0.14 for flood volume, while the highest RCV is obtained for $R C$ parameter, 0.005-0.009 for peak discharge and 0.14-0.17 for flood volume. The effect of RC on uncertainty of flood features is found much higher compared to other base flow parameters.

The RCV values of peak discharge and flood volume estimated to assess the impact of loss parameters on flood features are presented in Figures 4(c)-4(d), respectively. An increase in RCV values of peak discharge and flood volume with the increase of rainfall duration is observed. Besides, the highest RCV values are found for IA parameters (2.36-2.62 


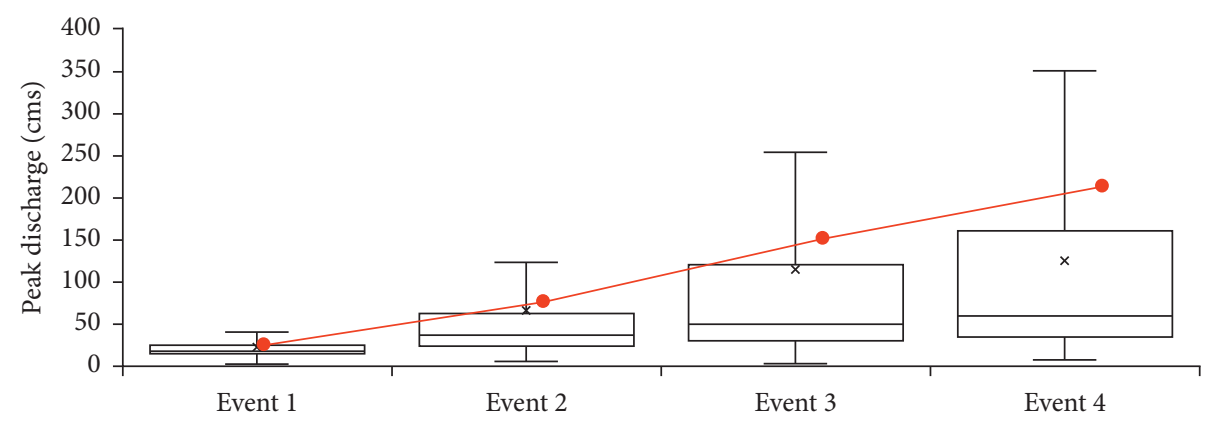

$\square$ Generated

$\rightarrow$ Observed

(a)

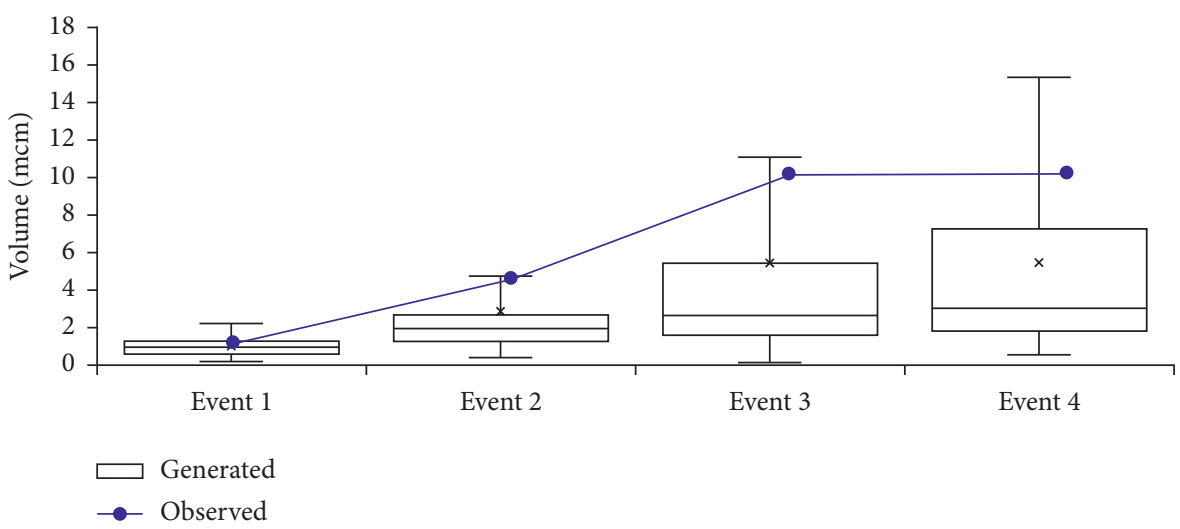

(b)

FIgURE 3: Comparison of observed and generated peak discharges and flood volumes.
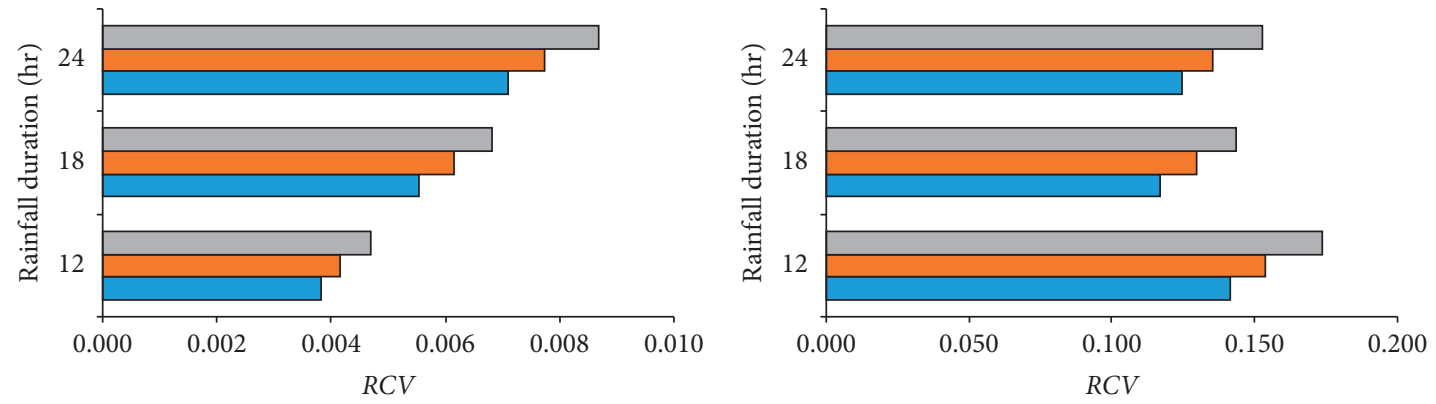

$\square R C$

$\square R F$

$\square I F$

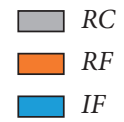

(a)

(b)

FIGURE 4: Continued. 


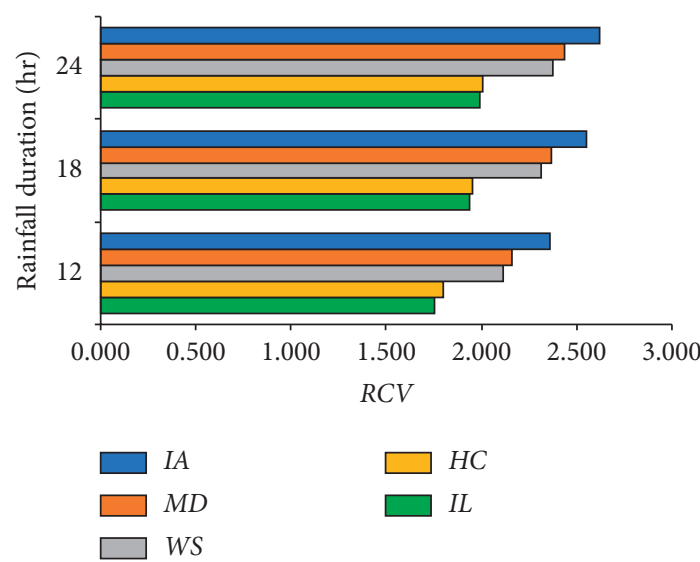

(c)



$L T$

(e)

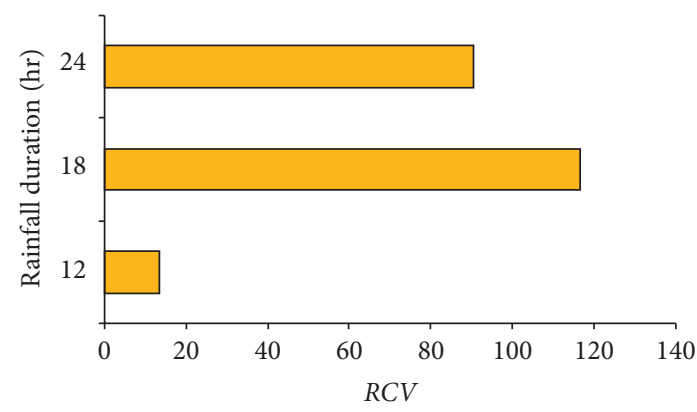

Rainfall depth

(g)

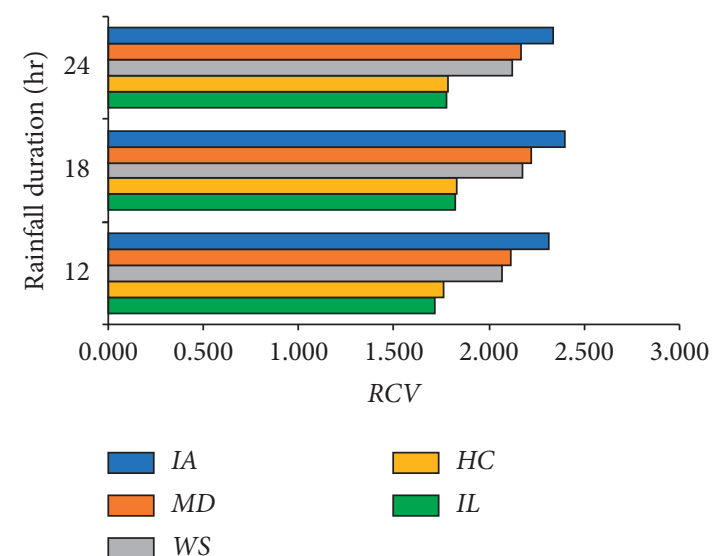

(d)

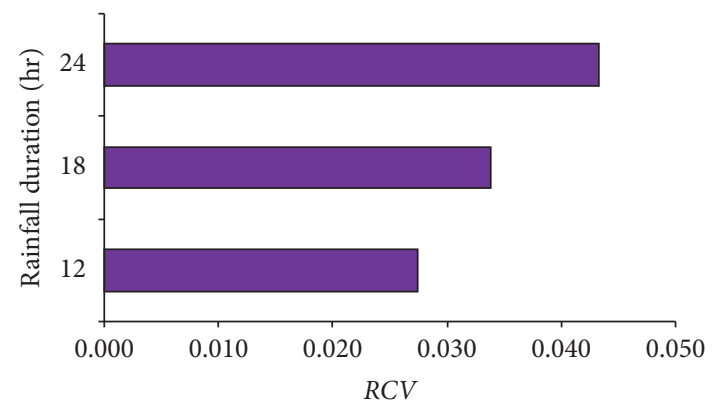

$L T$

(f)

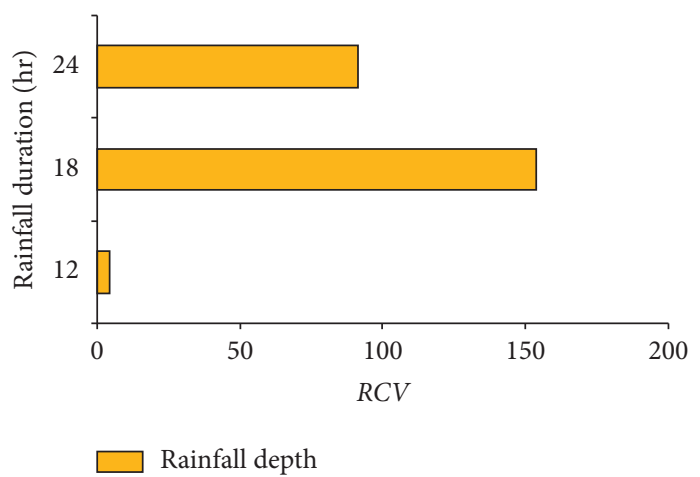

(h)

FIgURE 4: The impact of uncertainty in (a) base flow parameters on peak discharge, (b) base flow parameters on flood volume, (c) loss parameters on peak discharge, (d) loss parameters on flood volume, (e) unit hydrograph parameters on peak discharge, (f) unit hydrograph parameters on flood volume, (g) rainfall depth on peak discharge, and (h) rainfall depth on flood volume for different rainfall durations.

for peak discharge and 2.31-2.40 for flood volume). It means the impervious area has the highest impact on flood feature compared to other loss parameters. The variability of peak discharge and flood volume due to the uncertainty of the unit hydrograph parameter (LT) is estimated using RCV index and presented in Figures 4(e)-4(f), respectively. A decrease in peak discharge with an increase in rainfall duration is observed. In contrast, an increase in flood volume with an increase in rainfall duration is observed. The results indicate that uncertainty in unit hydrograph parameter has a negligible impact on peak discharge for long-duration rainfalls.
Figures $4(\mathrm{~g})-4(\mathrm{~h})$ represent the pattern of flood features uncertainty due to rainfall variability. The figures indicate a fluctuation in RCV values for both peak discharge and flood volume, where the highest RCV for peak discharge $(\mathrm{RCV}=116)$ and flood volume $(\mathrm{RCV}=153)$ are observed for $12 \mathrm{hr}$ rainfall duration. In general, the flood volume is found more sensitive to rainfall depth compared to peak discharge.

In Case 4, all of the hydrological parameters are considered random, and therefore, it is used to compare the influence of the hydrological parameters on flood hydrograph features. Total of 10000 random hydrographs are generated based on the stochastic hydrological parameters 


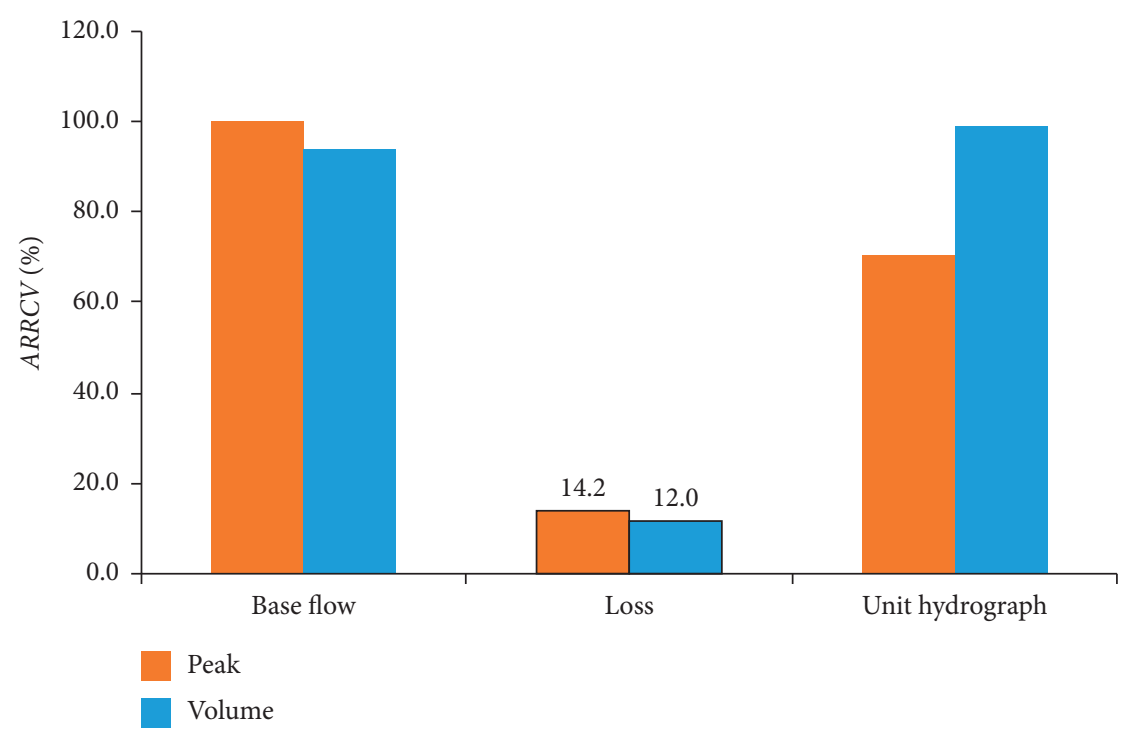

(a)

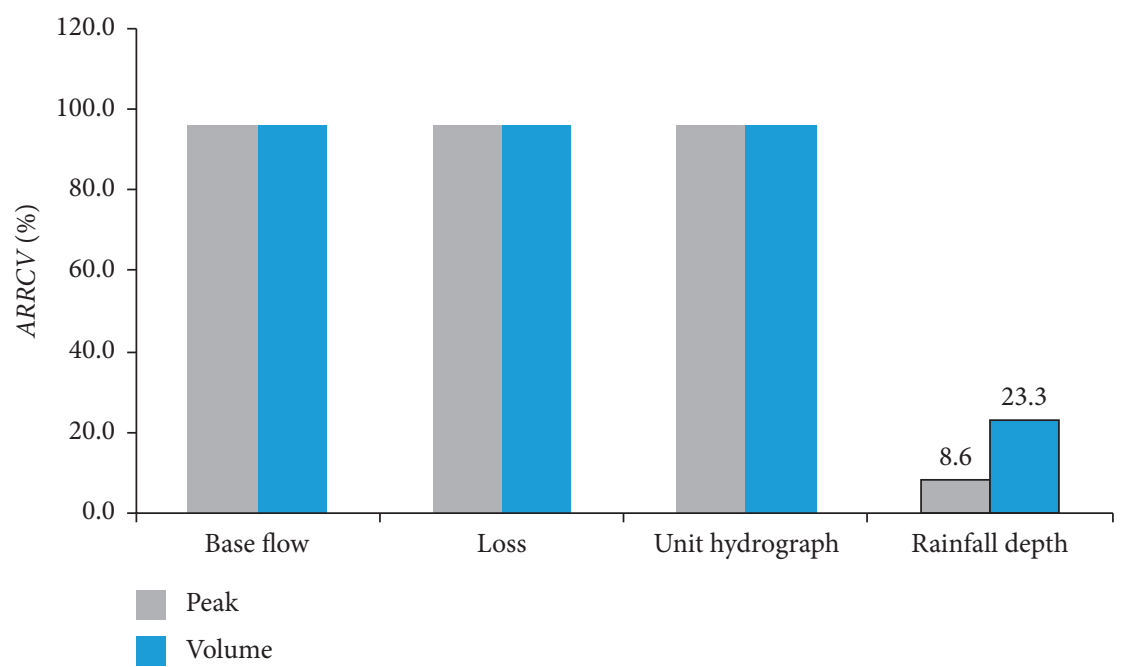

(b)

FIgURE 5: The ARRCV (in percentage) obtained for different hydrological components (baseflow, loss, unit hydrograph, and rainfall depth).

for this purpose. Similar to cases 1-3, hydrographs are generated for different rainfall durations. Obtained results are compared with those obtained in cases 1-3 using ARRCV index.

Figure 5(a) outlines the ARRCV values obtained for different hydrological components. The results show that the uncertainty in both peak discharge and flood volume is mostly associated with the loss parameters compared to other model parameters.

To assess the impact of the hydrological parameters as well as rainfall depth on flood hydrograph features, those are generated randomly in case 5 and compared with the results obtained in case 4 (Figure 5(b)). A significant impact on peak discharge and flood volume is observed due to variability in rainfall depth. Overall, the results reveal that loss parameters have the highest impact on flood features among hydrological parameters, while the base flow parameters have the lowest impact. Besides, rainfall depth has higher impact on flood hydrograph features compared to hydrological parameters.

\section{Conclusions}

Uncertainties in flood hydrograph features, namely peak discharge and flood volume due to uncertainty in rainfall and hydrological model parameters are assessed in this study. The flood hydrograph is generated using the HECHMS model from rainfall events generated using RPG. The PDF is used to estimate the uncertainty in HEC-HMS parameters, including the loss, base flow, and unit hydrograph parameters. The RCV and ARRCV indices are used to estimate the influence of different parameters on flood peak and volume. The highest RCV values for flood peak and flood volume are found as 116 and 153, respectively, for a $12 \mathrm{hr}$ duration rainfall event. This indicates that flood volume is more sensitive to uncertainty in the hydrological 
model and rainfall parameters compared to flood peak. Rainfall depth is found to have more influence on flood peak and volume compared to rainfall duration. The ARRCV index calculated for different hydrological parameters also indicates the highest impact of rainfall depth on uncertainty in flood hydrograph features.

As limitation of the current research, the proposed approach is examined on a single basin. However, employing more basins can provide a better perspective on the uncertainty analysis of flood features. Thus, this issue can be studied in future studies. Furthermore, several uncertainties sources related to the model configuration, data, and study period are missed in the current study, which can be considered to provide robust findings in future investigations.

\section{Data Availability}

The data used to support the findings of this study are available from the corresponding author upon request.

\section{Conflicts of Interest}

The authors declare have no conflicts of interest.

\section{References}

[1] K. Ahmed, E.-S. Chung, J.-Y. Song, and S. Shahid, "Effective design and planning specification of low impact development practices using water management analysis module (WMAM): case of Malaysia," Water, vol. 9, no. 3, p. 173, 2017.

[2] Z. Eslami, S. Shojaei, and M. A. Hakimzadeh, "Exploring prioritized sub-basins in terms of flooding risk using HEC_ HMS model in Eskandari catchment, Iran," Spatial Information Research, vol. 25, no. 5, pp. 677-684, 2017.

[3] J. Høybye and D. Rosbjerg, "Effect of input and parameter uncertainties in rainfall-runoff simulations," Journal of Hydrologic Engineering, vol. 4, pp. 214-224, 1999.

[4] M. S. Nashwan, T. Ismail, and K. Ahmed, "Flood susceptibility assessment in Kelantan river basin using copula," International Journal of Engineering \& Technology, vol. 7, no. 2, pp. 584-590, 2018.

[5] S. H. Pour, A. K. A. Wahab, S. Shahid, and M. Asaduzzaman, A. Dewan, "Low impact development techniques to mitigate the impacts of climate-change-induced urban floods: current trends, issues and challenges," Sustainable Cities and Society, vol. 62, p. 102373, 2020.

[6] A. J. Dewan and G. M. Hornberger, "How much complexity is warranted in a rainfall-runoff model?" Water Resources Research, vol. 29, no. 8, pp. 2637-2649, 1993.

[7] S. Uhlenbrook, J. Seibert, C. Leibundgut, and A. Rodhe, "Prediction uncertainty of conceptual rainfall-runoff models caused by problems in identifying model parameters and structure," Hydrological Sciences Journal, vol. 44, no. 5, pp. 779-797, 1999.

[8] D. L. Shrestha, Uncertainty Analysis in Rainfall-Runoff Modelling: Application of Machine Learning Techniques, IHE Delft Institute for Water Education, Delft, Netherlands, 2009.

[9] K. J. Beven, Rainfall-Runoff Modelling: The Primer, John Wiley \& Sons, Hoboken, NJ, USA, 2011.

[10] Z. Li, Q. Shao, Z. Xu, and X. Cai, "Analysis of parameter uncertainty in semi-distributed hydrological models using bootstrap method: a case study of SWAT model applied to Yingluoxia watershed in northwest China," Journal of $\mathrm{Hy}$ drology, vol. 385, no. 1-4, pp. 76-83, 2010.

[11] Y. Liu and H. V. Gupta, "Uncertainty in hydrologic modeling: toward an integrated data assimilation framework," Water Resources Research, vol. 43, 2007.

[12] S. Maskey and R. K. Price, "Uncertainty Issues in flood forecasting," Flood Events Are We Prepared, pp. 123-136, 2003.

[13] A. Sharafati and B. Zahabiyoun, "Rainfall threshold curves extraction by considering rainfall-runoff model uncertainty," Arabian Journal for Science and Engineering, vol. 39, 2014.

[14] T. Wagener and H. V. Gupta, "Model identification for hydrological forecasting under uncertainty," Stochastic Environmental Research and Risk Assessment, vol. 19, no. 6, pp. 378-387, 2005.

[15] A. Sharafati and E. Pezeshki, "A strategy to assess the uncertainty of a climate change impact on extreme hydrological events in the semi-arid Dehbar catchment in Iran," Theoretical and Applied Climatology, vol. 139, no. 1-2, pp. 389-402, 2020.

[16] A. Afshar and M. A. Mariño, "Optimizing spillway capacity with uncertainty in flood estimator," Journal of Water Resources Planning and Management, vol. 116, no. 1, pp. 71-84, 1990.

[17] A. Afshar, A. Barkhordary, and M. A. Mariño, "Optimizing river diversion under hydraulic and hydrologic uncertainties," Journal of Water Resources Planning and Management, vol. 120, no. 1, pp. 36-47, 1994.

[18] A. Afshar, A. Rasekh, and M. H. Afshar, "Risk-based optimization of large flood-diversion systems using genetic algorithms," Engineering Optimization, vol. 41, no. 3, pp. 259-273, 2009.

[19] J. Lee, J. Choi, O. Lee, J. Yoon, and S. Kim, "Estimation of probable maximum precipitation in Korea using a regional climate model," Water, vol. 9, no. 4, p. 240, 2017.

[20] K. J. Beven, "Rainfall-runoff modeling: introduction," in Encyclopedia of Hydrological Sciences, Wiley, Hoboken, NJ, USA, 2005.

[21] R. K. Srivastav, A. Schardong, and S. P. Simonovic, "Equidistance quantile matching method for updating IDFCurves under climate change," Water Resources Management, vol. 28, no. 9, pp. 2539-2562, 2014.

[22] A. S. Rahman, A. Rahman, M. A. Zaman, K. Haddad, A. Ahsan, and M. Imteaz, "A study on selection of probability distributions for at-site flood frequency analysis in Australia," Natural Hazards, vol. 69, no. 3, pp. 1803-1813, 2013.

[23] M. Noor, T. bin Ismail, S. Ullah, Z. Iqbal, N. Nawaz, and K. Ahmed, "A non-local model output statistics approach for the downscaling of CMIP5 GCMs for the projection of rainfall in Peninsular Malaysia," Journal of Water and Climate Change, 2019.

[24] M. Noor, T. Ismail, S. Shahid, M. S. Nashwan, and S. Ullah, "Development of multi-model ensemble for projection of extreme rainfall events in Peninsular Malaysia," Hydrology Research, vol. 50, no. 6, pp. 1772-1788, 2019.

[25] M. Noor, T. Ismail, E.-S. Chung, S. Shahid, and J. Sung, "Uncertainty in rainfall intensity duration frequency curves of peninsular Malaysia under changing climate scenarios," Water, vol. 10, no. 12, p. 1750, 2018.

[26] J. E. Reynolds, S. Halldin, J. Seibert, C. Y. Xu, and T. Grabs, "Flood prediction using parameters calibrated on limited discharge data and uncertain rainfall scenarios," Hydrological Sciences Journal, vol. 65, no. 9, pp. 1512-1524, 2020. 
[27] L. Hu, E. I. Nikolopoulos, F. Marra, and E. N. Anagnostou, "Sensitivity of flood frequency analysis to data record, statistical model, and parameter estimation methods: an evaluation over the contiguous United States," Journal of Flood Risk Management, vol. 13, 2020.

[28] J. Huang, J. Wen, B. Wang, and O. Hinokidani, "Parameter sensitivity analysis for a physically based distributed hydrological model based on Morris' screening method," Journal of Flood Risk Management, vol. 13, 2020.

[29] U. C. Nkwunonwo, M. Whitworth, and B. Baily, "A review of the current status of flood modelling for urban flood risk management in the developing countries," Scientific African, vol. 7, p. e00269, 2020.

[30] S. Sharma, Y.-J. Kwak, R. Kumar, and B. Sarma, "Analysis of hydrological sensitivity for flood risk assessment," ISPRS International Journal of Geo-Information, vol. 7, no. 2, p. 51, 2018.

[31] M. N. Cheshmidari, A. H. Hatefi Ardakani, H. Alipor, and S. Shojaei, "Applying Delphi method in prioritizing intensity of flooding in Ivar watershed in Iran," Spatial Information Research, vol. 25, no. 2, pp. 173-179, 2017.

[32] hamid Pahlavani, A. A. Dehghani, A. R. Bahremand, and S. Shojaei, "Intelligent estimation of flood hydrographs using an adaptive neuro-fuzzy inference system (ANFIS). Model," Earth Systems and Environment, vol. 3, 2017.

[33] Y. K. Tung, "Uncertainty analysis of National Weather Service rainfall frequency atlas," Journal of Hydraulic Engineering, vol. 113, no. 2, pp. 179-189, 1987.

[34] S. Maskey and V. Guinot, "Improved first-order second moment method for uncertainty estimation in flood forecasting," Hydrological Sciences Journal, vol. 48, no. 2, pp. 183-196, 2003.

[35] C. S. Melching, "An improved first-order reliability approach for assessing uncertainties in hydrologic modeling," Journal of Hydrology, vol. 132, no. 1-4, pp. 157-177, 1992.

[36] S.-J. Wu, H.-C. Lien, and C.-H. Chang, "Modeling risk analysis for forecasting peak discharge during flooding prevention and warning operation," Stochastic Environmental Research and Risk Assessment, vol. 24, no. 8, pp. 1175-1191, 2010.

[37] M. B. Butts, J. T. Payne, M. Kristensen, and H. Madsen, “An evaluation of the impact of model structure on hydrological modelling uncertainty for streamflow simulation," Journal of Hydrology, vol. 298, no. 1-4, pp. 242-266, 2004.

[38] J. N. Díaz-Ramírez, "Assessment of uncertainty in flow model parameters, channel hydraulic properties, and rainfall data of a lumped watershed model," Mississippi State University, Doctoral dissertation, Starkville, MS, USA, 2007.

[39] Y. Hong, K. Hsu, H. Moradkhani, and S. Sorooshian, "Uncertainty quantification of satellite precipitation estimation and Monte Carlo assessment of the error propagation into hydrologic response," Water Resources Research, vol. 42, 2006.

[40] L. S. Kuchment, A. N. Gelfan, and V. N. Demidov, Application of Dynamic-Stochastic Runoff Generation Models for Estimating Extreme Flood Frequency Distributions, pp. 107-114, International Association of Hydrological Sciences, Wallingford, UK, 2003.

[41] L. S. Kuchment and A. N. Gelfan, "Dynamic-stochastic models of rainfall and snowmelt runoff formation," Hydrological Sciences Journal, vol. 36, no. 2, pp. 153-169, 1991.

[42] G. Kuczera and E. Parent, "Monte Carlo assessment of parameter uncertainty in conceptual catchment models: the Metropolis algorithm," Journal of Hydrology, vol. 211, no. 1-4, pp. 69-85, 1998.
[43] R. H. McCuen, "Uncertainty analyses of watershed time parameters," Journal of Hydrologic Engineering, vol. 14, no. 5, pp. 490-498, 2009.

[44] R. Ronalds and H. Zhang, "Assessing the impact of urban development and on-site stormwater detention on regional hydrology using Monte Carlo simulated rainfall," Water Resources Management, vol. 33, no. 7, pp. 2517-2536, 2019.

[45] P.-S. Yu, T.-C. Yang, and S.-J. Chen, "Comparison of uncertainty analysis methods for a distributed rainfall-runoff model," Journal of Hydrology, vol. 244, no. 1-2, pp. 43-59, 2001.

[46] R. R. Shrestha and F. Nestmann, "Physically based and datadriven models and propagation of input uncertainties in river flood prediction," Journal of Hydrologic Engineering, vol. 14, no. 12, pp. 1309-1319, 2009.

[47] G. Aronica, B. Hankin, and K. Beven, "Uncertainty and equifinality in calibrating distributed roughness coefficients in a flood propagation model with limited data," Advances in Water Resources, vol. 22, no. 4, pp. 349-365, 1998

[48] K. Beven and J. Freer, "Equifinality, data assimilation, and uncertainty estimation in mechanistic modelling of complex environmental systems using the GLUE methodology," Journal of Hydrology, vol. 249, no. 1-4, pp. 11-29, 2001.

[49] S. Golian, B. Saghafian, M. Elmi, and R. Maknoon, "Probabilistic rainfall thresholds for flood forecasting: evaluating different methodologies for modelling rainfall spatial correlation (or dependence)," Hydrological Processes, vol. 25, no. 13, pp. 2046-2055, 2011.

[50] S. Golian, B. Saghafian, and R. Maknoon, "Derivation of probabilistic thresholds of spatially distributed rainfall for flood forecasting," Water Resources Management, vol. 24, no. 13, pp. 3547-3559, 2010.

[51] V. Merwade, F. Olivera, M. Arabi, and S. Edleman, "Uncertainty in flood inundation mapping: current issues and future directions," Journal of Hydrologic Engineering, vol. 13, no. 7, pp. 608-620, 2008.

[52] A. Montanari, "Large sample behaviors of the generalized likelihood uncertainty estimation (GLUE) in assessing the uncertainty of rainfall-runoff simulations," Water Resources Research, vol. 41, 2005.

[53] P. M. Younger, J. E. Freer, and K. J. Beven, "Detecting the effects of spatial variability of rainfall on hydrological modelling within an uncertainty analysis framework," Hydrological Processes, vol. 23, no. 14, pp. 1988-2003, 2009.

[54] A. Sharafati, A. Tafarojnoruz, and Z. M. Yaseen, "New stochastic modeling strategy on the prediction enhancement of pier scour depth in cohesive bed materials," Journal of Hydroinformatics, vol. 22, 2020.

[55] M. Borga, P. Boscolo, F. Zanon, and M. Sangati, "Hydrometeorological analysis of the 29 August 2003 flash flood in the eastern Italian alps," Journal of Hydrometeorology, vol. 8, no. 5, pp. 1049-1067, 2007.

[56] M. S. Nashwan, S. Shahid, and N. Abd Rahim, "Unidirectional trends in annual and seasonal climate and extremes in Egypt," Theoretical and Applied Climatology, vol. 136, no. 1-2, pp. 457-473, 2019.

[57] A. Sharafati and H. M. Azamathulla, "Assessment of dam overtopping reliability using SUFI based overtopping threshold curve," Water Resources Management, vol. 32, no. 7, pp. 2369-2383, 2018.

[58] A. Sharafati, Z. M. Yaseen, and E. Pezeshki, "Strategic assessment of dam overtopping reliability using a stochastic process approach," Journal of Hydrologic Engineering, vol. 25, no. 7, p. 04020029, 2020. 